\title{
Instilling the System of Values in Preschool Children in the Cultural and Educational Space
}

\author{
Larysa V. Zdanevych,", Yuliia V. Syrova ${ }^{2}$, Svitlana V. Kolosova², Maryna S. Pyvovarenko², \\ Olha O. Kurhannikova ${ }^{3}$
}

\begin{abstract}
${ }^{1}$ Department of Pre-School Pedagogy, Psychology and Professional Methods, Faculty of Pre-School Education and Psychology, Khmelnytskyi Humanitarian-Pedagogical Academy, 29000, Khmelnytskyi, Ukraine

${ }^{2}$ Department of Theory and Methods of Preschool Education, Faculty of Preschool and Special Education and History, Municipal Establishment "Kharkiv Humanitarian Pedagogical Academy” of Kharkiv Regional Council, 61001, Kharkiv, Ukraine ${ }^{3}$ Department of Foreign Philology, Faculty of Social and Pedagogical Sciences and Foreign Philology, Municipal Establishment “Kharkiv Humanitarian Pedagogical Academy” of Kharkiv Regional Council, 61001, Kharkiv, Ukraine
\end{abstract}

Received August 28, 2020; Revised October 1, 2020; Accepted November 1, 2020

\section{Cite This Paper in the following Citation Styles}

(a): [1] Larysa V. Zdanevych, Yuliia V. Syrova, Svitlana V. Kolosova, Maryna S. Pyvovarenko, Olha O. Kurhannikova , "Instilling the System of Values in Preschool Children in the Cultural and Educational Space," Universal Journal of Educational Research, Vol. 8, No. 11B, pp. 5991 - 5999, 2020. DOI: 10.13189/ujer.2020.082235.

(b): Larysa V. Zdanevych, Yuliia V. Syrova, Svitlana V. Kolosova, Maryna S. Pyvovarenko, Olha O. Kurhannikova (2020). Instilling the System of Values in Preschool Children in the Cultural and Educational Space. Universal Journal of Educational Research, 8(11B), 5991 - 5999. DOI: 10.13189/ujer.2020.082235.

Copyright $\odot 2020$ by authors, all rights reserved. Authors agree that this article remains permanently open access under the terms of the Creative Commons Attribution License 4.0 International License

\begin{abstract}
The research was conducted in order to establish the most effective ways of forming a general system of values in preschool children. Emphasis is placed on the unification of methods of moral and ethical education of 3-6-year-old children, and the development of educational model that would contribute to the child's optimal understanding of basic moral principles of mankind. In this regard, the experiment was conducted on a research group consisting of 710 children aged 3-6, which also included 192 parents and 50 teachers. In addition, 52 books of short stories and fairy tales were selected for the study, on the basis of which the main value preferences and orientations of preschool children were determined. According to the preferences of children, parents or teachers, certain texts were selected from the defined 52 stories and fairy tales for detailed textual analysis for children to differentiate the most common moral values, the range of which was also clearly defined and limited to 20 concepts. As a result of the study, children often paid attention to the values of happiness, peace, cooperativeness and honesty. Beauty, kindness, friendship and purity also attracted significant attention of preschoolers. However, for example, avail, humility, tolerance, hospitality and respect were rarely emphasized by children. Patriotism as a value has generally gone unnoticed. The results of the
\end{abstract}

study might be used as auxiliary material for teachers in the preparation and selection of teaching materials in terms of value orientations in preschool children, as well as in the parents' choice of children's literature that would clearly reflect the inner world of the child and be understood in terms of axiological component.

Keywords Preschool Children, Moral Values, Worldview, Preschool Education, Stories, Fairy Tales

\section{Introduction}

Value is a concept that includes everything that is acceptable and important to the individual. Such branches of science as philosophy, ethics, aesthetics, and sociology consider value as a product of human life in certain historical, cultural, and socio-political conditions. There are also different groups of values in certain areas of human life. In particular, we are talking about values-goods (family, happiness, health, friendship, beauty, creativity, money, etc.), and values-regulations (empathy, independence, curiosity, purposefulness, confidence, courage, perseverance, etc.). 
The issue of determining the range of values that a preschool establishment should instill is debatable, problematic and difficult, because a preschool child is still unable to navigate in the value field of modern culture or to make conscious life choices. The system of values in preschool children is, in fact, the system of values of adults (parents). Accordingly, in a preschool establishment, the teacher with his system of values also significantly influences the formation of the child's personality.

If we consider the system of education in the humanistic paradigm, the system of child's spiritual and moral values is formed inseparably from the child's personality. That is, they teach a child =being open to the world and people, cultivating skills of social behaviour, having conscious attitude to himself as a free independent personality, forming a list of responsibilities, determining their nature by relationships with others, developing the ability to perceive different information, comprehend it, and apply for certain needs.

The development of a child up to the moment of school education is fundamental in the aspect of formation of the axiological component of child's character. First of all, it concerns the peculiarities of the child's communication with parents, preschool teachers, society, where the individual begins to join the cultural and historical experience of mankind or an ethnic group, acquires basic communication skills, and generally forms an idea of the environment and the world.

Given that preschool education is an independent part of the educational process, the closest in essence to family education, its defining feature is that it is essentially the primary link in the process of socialization of an individual. Preschool establishment is the first, new, alien, so it is uncomfortable environment for a child, where he, not yet developed and integral, first encounters a kind of micro-society and where he demonstrates its ability (level and quality) to socialize. Accordingly, it is difficult and at the same time important to form in a young individual, who is actually under stress, a clear idea of the basics and norms of social relations and interaction, as well as instilling basic values that will help the child make the right choices in particular situations.

Therefore, the research aims at visualizing the scheme of the hierarchical system of values of a preschool child, which will be based on binary oppositions, where the most archetypal is the opposition "good/evil", and also to consider possible ways of achievement of high pedagogical that results in the course of integration of the child aged 3 to 6 in cultural and educational space of preschool institution with the help of analysis and scientific ideas in terms of forming values of preschoolers in various spheres of human activity.

\section{Literature Review}

In world pedagogical practice, moral education or instilling the system of values is usually considered in the paradigm of teaching pupils to understand the difference between right and wrong. Teachers in this aspect qualify as moral educators, as they teach by methods of both individual and group learning [1].

In addition, researchers often focus on the child's adaptation to preschool establishment, as this is crucial for the well-being of small children and the formation of their moral values. The education system works in such conditions that almost every child must attend kindergarten before entering school. In this case, children have to cope with the first stage of socialization outside the family environment, where they face many problems, which not only determine their first "school of experience", but also create the background for potential long-term harmful implications [2, 3].

In practice, the organization of a child's life activity in a preschool establishment is the main factor in the full development of this child. The way of arranging life of a preschooler gives him the opportunity to live, accumulate, and realize his life experience, which, in turn, is seen as part of human consciousness, and it shapes person's behavioural phenomena, habits, etc. [4].

People living in society need socialization. Maintaining social relations, they study the behaviour approved by society. Thanks to the curricula of preschool establishments, children are systematically taught to take on responsibilities, cooperate, help, and develop a habit of constructively building positive relationships with others. At the same time, the psychosocial development of six-year-olds attending preschool establishment is influenced by the sociocultural and educational level of their parents, the year of attending preschool establishment, the socio-economic level of the family, the sex of the child, the number of siblings, as well as the teacher's status and the curriculum [5].

Some theorists of pedagogical science believe that the social and emotional competence of preschool children directly affects later learning, social, and psychological outcomes. Children who are socially and emotionally competent have a better chance of successfully interact with peers, find more friends, have better relationships with parents and teachers, and achieve greater academic and social success. Children who lack social and emotional competence are at risk of reduced social opportunities, deviations, behavioural disorders, performance and achievement problems [6].

In addition, researchers pay attention to the views of children themselves on moral and everyday issues, rules and participation in the daily life of the establishment. As a result, children usually focus on the so-called "Correct behaviour," which involves both caring for the well-being of others and social order in school, including adherence to rules and discipline [7].

Some studies theoretically substantiate and experimentally confirm the importance of Olympic 
education as a factor in the socialization of preschoolers. Moreover, the socialization of preschoolers is defined as an individual and personal achievement in the process of Olympic education, formed by the balance of appropriate understanding of sports, values of Olympic culture, interests, needs and values that determine the so-called Olympic patterns of behaviour [8].

Instilling values is possible in the aspect of introduction of gender-flexible pedagogy, in particular the concept, which includes ideas on modelling by preschool staff of alternative forms of masculinity and femininity, the importance of mixed-gender workforce, and literate gender education in the curricula. These studies suggest that gender practices root in implicit gender beliefs of educators, which, in turn, influence larger socio-political discourses [9].

There are studies [10] in the world pedagogical practice, which indicate that the curricula and educational process in preschool establishment should focus on the development of fantasizing skills in children, as this may be an important factor in development of critical socialization skills, such as emotion regulation.

In general, the interaction between the mind and emotions, as well as the corresponding need to cultivate these emotions [11] is one of the fundamental tasks in terms of international pedagogical experience.

However, despite the diversity of scientific theories and approaches to determining ways of instilling the system of values in preschool children, the issue of the conceptual spectrum and nature of the hierarchy of values remains topical.

\section{Materials and Methods}

The object of research is value orientations as a basis of moral and ethical education of a preschool child. The objective is to determine the ways and methods of instilling the system of values in preschool children. With the help of a representative sample, we formed an experimental group, which consisted of 710 children, 192 parents, and 50 teachers. We also determined 52 texts of stories and fairy tales for the work of the members of the experimental group [12].

Besides, we identified two different data collection tools, including different interview forms and lists of values consisting of 20 abstract concepts (see Appendix A).

Thus, we identified three forms of interviews for children aged 3 to 6 , parents, and teachers. We used these three forms to determine which of the proposed abstract concepts children liked the most in certain texts of stories and fairy tales. In particular, we asked children to name stories or fairy tales that they liked the most and that they would like to study with their parents or teachers.

One of the data collection tools used in the study is the list of values, which was formed in accordance with expert opinions [13], as well as in accordance with the UNESCO List of Values [14], which consists of twelve values (see Appendix B).

\section{Results}

The process of conscious assimilation by an individual of a certain system of knowledge, norms, values lasts a lifetime and directly depends on social competence, which, in turn, is modelled of a number of psychological markers, including temperament, character, abilities, talents, traumas, etc. Modern society is so complex that we cannot learn everything we need just by communicating with our parents for 15 years. Accordingly, society created such institutions as secondary schools, universities, vocational schools to provide the necessary training. It has become natural for people to spend more than 25 years in these institutions (the average duration of professional activity is almost the same), preparing to fulfil their future social role [15].

In fact, this social role is largely the result of the work of teachers, parents, preschool establishment and other educational institutions, which to a greater or lesser extent shape the personality. The formation or accumulation of values is continuous, while age and environment play an important role in this process. The socialization of a preschool child occurs under the influence of several factors, including the macro level (socio-political situation in the country, social order, etc.), meso level (ethnocultural and religious specifics of the environment), and micro level (family, educational institution, out-of-school environment, etc.).

The life of modern society is very dynamic; therefore, preschool children have much more socio-economic opportunities than their peers, for example, 10 years ago. The level and quality of life are growing, and the children's entertainment industry is also developing (movies, virtual games, Internet access, etc.), while there is a downward gradation in terms of the development of child's physical, mental, moral and spiritual health.

The challenges of the modern world, socio-political crises, economic instability, wars, and armed conflicts indicate that it is now important to strengthen the emphasis on instilling the axiological component in children and youth, which can become a psychological "shield" for the younger generation in overcoming problems. In particular, with regard to preschoolers, it will be important for them to conduct a set of exercises and classes that would be a kind of introduction to the study of tolerance in both universal, ethnic and national senses (especially in large cities where the population is polyethnic), justice, empathy, mutual assistance, ecological perception of the environment, the concept of patriotism in theoretical and practical terms, etc. In addition, a number of universal values, which form the basis of the ideas of the average person, are no less 
important. These are, in particular, good/evil, love/hate, beauty/ugliness, joy/sadness (pain), courage/fear, etc.

According to the observations of psychologists, television and computer images and characters, which fill the child's consciousness, significantly transform the child's imaginary worldview, leading to the formation of a deliberately deformed value system. The worldviews of any child are closely intertwined with the mythological world perception, which can be the basis for building an approximate scheme of the system of values, which would be convenient to use in preschool education as a universal model.

The child in a special way creates an idea of this world, according to which everything has its place; and in general life is organized around the individual, i.e. the child. In other words, the center of the world in the child's imagination is the child himself, and there are, as in mythological stories, various phenomena of the world around, represented by a particular sensory zoo- or anthropomorphic image-symbol, which, given the peculiarities of the child's thinking, performs a certain sacred function. Accordingly, fairy tales and myths, the plots of which are most easily superimposed on children's imagination, are important for preschool children in the aspect of instilling the system of values.

To begin the process of socialization of the preschooler, it is necessary to acquaint him with the ethnocultural system of folk tales and myths in order to replace the dominance of modern TV and Internet products with often distorted and destructive images to the maximum possible extent, and balance the development of children's personality. If this link was missed in family education, the preschool establishment will take on the role of instilling cultural values in the national and universal dimensions.

The period of preschool education includes the so-called preoperative stage of child's cognitive development (2 to 7 years, according to the theory of the Swiss psychologist Piaget [16]). During this period, children acquire the ability of language. Words-symbols are determined by their personal (egocentric) experience and, for the most part, are over-concretized. In this period, children mainly show the ability to imagine past and present events, experiences and concepts through words, expressions, gestures or other familiar means. Accordingly, the system of concepts that mean certain moral and ethical values is best interpreted in the context of a discourse already known to the child, well-known concepts and symbols [16]. For example, you can detail the abstract concepts of good and evil with the help of ordinary conversations with the child on the actions of the main or secondary characters of fairy tales, more precisely - the qualities of these actions, the impact (positive or negative) on other characters and so on.

Moral development of an individual is directly related to intellectual development. The primary stage of the former is preoperative [16], "prelogical" one, which lasts approximately 2 to 7 years, and is based mainly on egocentrism. This stage is characterized by moral realism, when the child perceives the norms and rules of behaviour as immutable, indisputable principles, the violation of which entails strict responsibility [16]. In this context, our theory of instilling values in preschool children can be easily implemented due to the favourable stage of their moral development, because children will perceive all theories, judgments, warnings as the absolute truth. An important point here is the correct structure of educational discourse, the choice of the necessary methods and verbal material.

In the most general sense, a child who enters a preschool establishment is directly influenced by a limited number of factors, but they are the key to the process of instilling the system values. Table 1 is a schematic representation of these factors.

The scheme shows the points of contact of the most important people for the child, in particular parents or those who perform this function. The planes of the child's psyche and parental influence are completely tangential. At the same time, the core of a child's personality is a set of his own ideas about the world and ideas about himself, which are the result of a kind of "genetic lottery", i.e. a set of genetic traits. Society, peers, relatives, and teachers influence the formation of the child's personality more sporadically, but the level of these influences can vary and be stronger, depending on the psychological basis of an individual.

Table 1. Picture of mental influences on the preschooler's personality

\begin{tabular}{|c|c|c|}
\hline Society & $\begin{array}{c}\text { Representations of this world, natural } \\
\text { phenomena, cosmic phenomena, processes, } \\
\text { animals, strangers, etc. }\end{array}$ & Peers \\
\hline $\begin{array}{c}\text { Father } \\
\text { (grandfather, generally a man who is } \\
\text { close) }\end{array}$ & Preschool child & $\begin{array}{c}\text { Mother } \\
\text { (grandmother, aunt, generally a woman } \\
\text { who is close) }\end{array}$ \\
\hline Relatives & $\begin{array}{c}\text { Awareness of their basic needs, desires, fears, } \\
\text { feelings, emotions, etc. }\end{array}$ & Teachers \\
\hline
\end{tabular}


Table 2. Values outlined in the stories and fairy tales that were provided by the experiment and read by different categories of respondents

\begin{tabular}{|c|c|c|c|c|}
\hline $\begin{array}{l}\text { List of values } \\
\text { Criteria of their differentiation }\end{array}$ & $\begin{array}{l}\text { Values outlined in stories and } \\
\text { fairy tales that were provided } \\
\text { by the experiment and } \\
\text { developed by experts }\end{array}$ & $\begin{array}{l}\text { Values outlined in } \\
\text { stories and fairy tales, } \\
\text { the texts of which } \\
\text { children aged } 3 \text { to } 6 \\
\text { chose independently }\end{array}$ & $\begin{array}{l}\text { Values outlined in } \\
\text { stories and fairy tales } \\
\text { chosen according to } \\
\text { parental tastes }\end{array}$ & $\begin{array}{l}\text { Values outlined in } \\
\text { stories and fairy tales } \\
\text { selected according to } \\
\text { the teachers' views }\end{array}$ \\
\hline happiness & 114 & 28 & 31 & 63 \\
\hline kindness & 101 & 19 & 20 & 57 \\
\hline Beauty & 86 & 43 & 49 & 42 \\
\hline friendship & 78 & 13 & 16 & 52 \\
\hline Purity & 35 & 7 & 20 & 14 \\
\hline self-interest & 30 & 9 & 8 & 19 \\
\hline Empathy & 20 & 8 & 7 & 9 \\
\hline responsibility & 10 & 5 & 5 & 4 \\
\hline Freedom & 9 & 5 & 1 & 2 \\
\hline Industry & 8 & 3 & 4 & 3 \\
\hline collaboration & 6 & 2 & 1 & 4 \\
\hline family unity & 4 & - & - & 4 \\
\hline obedience & 3 & 1 & 1 & 1 \\
\hline tolerance & 3 & 3 & 2 & 1 \\
\hline hospitality & 2 & 1 & 1 & 2 \\
\hline Respect & 2 & 2 & 2 & 2 \\
\hline Peace & 1 & - & - & 1 \\
\hline cooperation & 1 & - & 1 & - \\
\hline Honesty & 1 & 1 & 1 & 1 \\
\hline patriotism & - & - & - & - \\
\hline
\end{tabular}

The findings of this study showed variability in children's position in determining their moral values.

In particular, the results of the experiment obtained after the implementation of its first stage concerned the general identification of the existing values in the texts of stories and fairy tales selected for this experiment (a total of 52 texts). Table 2 shows the results of the surveys.

If we list the values that take place in the books of stories and fairy tales chosen for the experiment, happiness (114) is the most frequently mentioned concept. However, peace, cooperation, and honesty (1) are values mentioned once.

Kindness (101), beauty (86), friendship (78), purity (35), self-interest (30) are frequent values in the texts. The middle level involves empathy (20), responsibility (10), freedom (9), industry (8), and collaboration (6). We obtained these results through a textual analysis of stories and fairy tales conducted by experts, which proves that the value of peace is hardly mentioned in the texts of children's literature. According to a textual study of fiction books used by preschool teachers, the most recurring values in these texts are happiness and kindness, and the least recurring values are respect and peace. At the same time, patriotism is a value that is included in the list of 20 studied phenomena and is never mentioned in selected stories and fairy tales.

In the second stage of the experiment, we found out which abstract concept, that means a particular value, child mainly emphasizes in the books of stories and fairy tales and which he prefers.

The statistics given in Table 2 shows that the vast majority of children (43) preferred the aesthetic factor i.e. paid attention primarily to the external parameters of the 
characters and the attributive world. Family unity, peace and cooperation had no value for the children.

Happiness (28), kindness (19), friendship (13) were quite important for preschoolers, but kindness (9), empathy (8), purity (7), responsibility (5), freedom (5) attracted less attention of respondents. Even less important for them were industry (3), tolerance (3), collaboration (2), respect (2), obedience (1), honesty (1), and hospitality (1).

The reason for such an intense focus of preschoolers on aesthetic value, most likely, is the content of the world classics, which children chose for reading/studying. For example, the heroes of the texts Rapunzel, Snow White and the Seven Dwarfs, Sleeping Beauty, Cinderella are usually princes or princesses or generally beautiful characters, and the visual component for children aged 3 to 6 is always decisive.

Beauty (49) ranks first in the gradation of values that children paid attention to when studying the texts chosen by their parents in the case when children had the priority in the choice of texts. In the books that their parents read to them, the children did not attach any importance to the notion of family unity and peace. At the same time, happiness (31), kindness (20), friendship (16), purity (20) were values that preschoolers paid consistently much attention to, while self-interest (8), empathy (7), responsibility (5), industry (4) evoked slightly lower interest. Tolerance (2), respect (2), freedom (1), hospitality (1), cooperation (1), obedience (1), honesty (1), collaboration (1) are concepts that were rarely in view of children and parents.

Thus, the list of preferences of parents is close to the child's: in both cases, the aesthetic value is in the first place. Accordingly, this indicates that children interact more with their parents, choosing certain texts of books.

The hierarchy of values outlined in the books chosen by teachers is built close to expert evaluation. Thus, happiness (63) ranks first, and beauty (42) ranks only fourth. Obedience, peace, honesty, and tolerance are mentioned once. The concept of cooperation did not fall within the scope of study.

In general, the central values that children paid attention to in the books of stories and fairy tales chosen by teachers were kindness (57), friendship (52), self-interest (14), purity (14), and empathy (9). In addition, children attached importance to family unity (4), which was not the case in the two previous cases, collaboration (4), responsibility (4), and industry (3). The concepts of hospitality (2), freedom (2), and respect (2) were mentioned sporadically.

\section{Discussion}

Reviewing the international pedagogical scientific experience, we should note that Estonian teachers made similar attempts to outline the range of the system of values that a child needs to get in preschool, also from three positions. The only difference was the involvement of the position of directors of preschool establishments, in addition to parents and teachers. The range of the system of values differed in all three positions. For example, directors considered humour, pride, and ingenuity important, while teachers valued patience more, and parents considered confidence and devotion to be more important moral values [17].

In Sweden, preschool education is unique because it combines learning, game, care and instilling core values. Pedagogical research in Sweden often focuses on instilling three core values enshrined in the Swedish National Curriculum: children's rights, gender equality, and education for sustainable development [18]. These concepts are not included in the list of values we study, but they are becoming increasingly important in the modern world.

In the aspect of instilling the system of values, the world pedagogy actively considers the phenomenon of environmental awareness of preschool children in the context of psychological, pedagogical, organizational, and methodical capabilities of media education with the purpose of determining guiding principles $[19,20]$. The importance of environmental awareness, as well as environmental worldview at the present stage of development of society is crucial, while the ways and methods of instilling the system of values in these areas are a promising area of pedagogical research.

There are similar studies in the Russian pedagogical experience, in particular in terms of using the texts of fairy tales and stories as material. In particular, it is about Russians studying the problem of the pedagogical potential of Russian folk tales and their role in the interaction between preschoolers and educators. Thus, local scholars developed levels of cultural identity of the pedagogical potential of folk tales, which are characterized by ethnic specifics and ensure the formation of cultural identity of children [21]. In our opinion, such a research design is too narrow and limited to outline the range of moral and ethical values, and it is also difficult to apply to the pedagogical material of other countries. At the same time, the design we use is more universal, as it is based on universal values and is not burdened by ethnic specifics.

We should note that some studies in German pedagogy, relying on the experience of non-migrants, Turkish migrants and former Soviet migrants, also point to the importance of intercultural differences in views on the education of children from the perspective of parents and child care specialists [22]. In our opinion, it does not seem promising to focus the preschooler's attention on ethnicity in the current global integration processes.

The pedagogical experience of Finland show how nationality and ethnicity are realized in the daily practice of a preschool establishment. In particular, Finnish studies indicate that the liberal version of multiculturalism adopted in Finland strengthens the borders of the state, while 
promoting the formation of a strong system of values in preschool children, which is based primarily on tolerance. "Finnishness" is understood in the framework of the structure of everyday life. If we are talking about people who are considered "different", their cultural discourses are used as sources of their ethnic interpretation [23, 24]. In addition, multiculturalism leads to incorporation, in which individual and national values become the common value of all mankind [25]. Therefore, these studies prove that ethnic identity as an element of value-oriented education should not be determined by a self-sufficient principle, much less overemphasize it, but rather unify the value system, bringing it closer to international standards.

The scholars often propose solving the problem of creative and artistic development of preschoolers, as well as the problem of forming the axiological component of preschoolers in post-Soviet countries by means of:

(1). art [26, 27];

(2). by forming positive motivation in students majoring in Pedagogy for professional activity aimed at the development of creative individuality of senior preschoolers in the process of modelling problematic experimental situations of interdisciplinary content in practical classes, being as close as possible to real interaction with children [28];

(3). by applying methods of the so-called "creative (artistic) pedagogy" [29];

(4). "museum pedagogy" [30];

(5). transformation of the subject-spatial environment in preschool establishments [31].

Such approaches to the formation of the system of values seem somewhat outdated and ineffective, in particular, the results of these studies are more theoretical, and little extrapolated to empirical experience.

\section{Conclusions and Recommendations for Future Research}

The study confirmed that the values selected as the material for the experiment were mainly illustrated in the selected books for the experiment, which were read for children aged 3 to 6 . However, most children focused on the concept of happiness, while they were less interested in peace, cooperation and honesty.

Thus, the concept of happiness, which is much more meaningful in books and which is often emphasized by children, can be perceived as a reflection of children's inner world. Children like to be happy, to enjoy themselves, the world, to have fun, so a happy ending in the texts is important for them. Children quickly correlate happiness and sadness in books, show a high ability to understand the causes of sadness and the reasons for happiness or joy. At the same time, they are far from a depressing event and situation.

According to the results of the study, the concept of patriotism was left out of consideration. The possible cause was the international nature of the plots of the studied texts. However, a sense of unity, national solidarity must be instilled in preschool children. A child, who is full of universal love, will work for his country and society, will be happy and contribute to the development of his country.

In fact, those who acquired basic knowledge of patriotism in their childhood will fight for the welfare of their country in the future, will feel responsible for it, thriving to live in unity and solidarity, guided by laws, social and moral principles, love their country and respect its state values. Accordingly, the methods and ways of instilling patriotism in preschool children are open issues and need further study.

At the empirical level, the results of our study should be implemented in the form of seminars, printed leaflets or brochures, which would contain the most general information about a particular artistic text for preschoolers from the standpoint of its value content. This could make it easier for teachers and parents to choose how to implement the child's educational process.

The values that are interpreted in the texts of stories and fairy tales for preschool establishments must be clearly argued after reading/studying, and must be enshrined in the relevant types of educational activities.

The design of this experimental study can be applied to a wider range of artistic texts or videos (for example, cartoons), which influence the formation of axiological vectors of development of the child's personality.

\section{Appendix A}

Sample interviews for the study

- What is happiness (beauty, kindness, friendship, purity, self-interest, empathy, responsibility, freedom, industry, collaboration, family unity, obedience, tolerance, hospitality, respect, peace, cooperation, honesty, patriotism)?

- Which episode of the book do you remember the most?

- Which of the characters do you like the most?

- Why do you like this hero/heroine?

- What is this book about?

- Would you like to be like a particular character? Why?

- What is your favourite book? 


\section{Appendix B}

List of values selected for the study

\begin{tabular}{|c|}
\hline Happiness \\
\hline Kindness \\
\hline Beauty \\
\hline Friendship \\
\hline Purity \\
\hline self-interest \\
\hline Empathy \\
\hline Responsibility \\
\hline Freedom \\
\hline Industry \\
\hline Collaboration \\
\hline family unity \\
\hline Obedience \\
\hline Tolerance \\
\hline Hospitality \\
\hline Respect \\
\hline Peace \\
\hline Cooperation \\
\hline Honesty \\
\hline Patriotism \\
\hline
\end{tabular}

\section{REFERENCES}

[1] M. Thompson. Developing moral values in children: Observations from a preschool, IFE PsychologIA: An International Journal, Vol. 19, No 2, pp. 394-411, 2011.

[2] G. Amerijckx, P. Humblet. The transition to preschool: A problem or an opportunity for children? A sociological perspective in the context of a "Split system», European Early Childhood Education Research Journal, Vol. 23, No 1, pp. 99-111, 2015.

[3] A. Anning, J. Cullen, M. Fleer. Early Childhood Education: Society and Culture, SAGE Publications: London, 2008.

[4] B. Rous, R. Hallam, K. McCormick, M. Cox. Practices that support the transition to public preschool programs: Results from a national survey, Early Childhood Research Quarterly, Vol. 25, No 1, pp. 17-32, 2010.

[5] E. Dereli, E. Akaroglu. Factors that affect psycho-social development of preschool children in terms of art activities: Family and teacher of variables, Online Submission, USChina Education Review, Vol. 12, pp. 103-110, 2011.

[6] P. C. McCabe, M. Altamura. Empirically valid strategies to improve social and emotional competence of preschool children, Psychology in the Schools, Vol. 48, No 5, pp. 513-540, 2011.
[7] E. Johansson, C. Cobb-Moore, J. Lunn-Brownlee, S. Walker, G. Boulton-Lewis, J. Ailwood. Childrens perspectives on values and rules in Australian early education, Australasian Journal of Early Childhood, Vol. 39, No 2, pp. 12-20, 2014.

[8] Z. S. Varfolomeeva, I. A. Surinov. Olympic education as a factor of socialization of preschoolers, International Journal of Environmental and Science Education, Vol. 11, No 9, pp. 2495-2506, 2016.

[9] J. Warin, V. Adriany. Gender flexible pedagogy in early childhood education, Journal of Gender Studies, Vol. 26, No 4, pp. 375-386, 2015, doi: 10.1080/09589236.2015.110573 8.

[10] A. T., Gilpin, M. M. Brown, J. M. Pierucci. Relations between fantasy orientation and emotion regulation in preschool, Early Education and Development, Vol. 26, No 7, pp. 920-932, 2015.

[11] T. Lovat, K. Dally, N. Clement, R. Toomey. Values pedagogy and teacher education: Re-conceiving the foundations, Australian Journal of Teacher Education, Vol. 36, No 7, pp. 31-44, 2011.

[12] K. Thorpe, S. Statton, R. Morgan, S. Danby, C. Tayler. Testing the vision: Preschool settings as places for meeting, bonding and bridging, Children and Society, Vol. 26, No 4, pp. 328-340, 2012.

[13] S. H. Schwartz. An overview of the Schwartz theory of basic values, Online Readings in Psychology and Culture, Vol. 2, No 1, 2012, Online available from http://dx.doi.org/10.9707 /2307-0919.1116

[14] UNESCO (United Nations Educational, Scientific and Cultural Organisation). Roadmap for Implementing the Global Action Programme on Education for Sustainable Development, United Nations Educational, Scientific and Cultural Organization, France, 2014.

[15] P. Ülavere, M. Veisson. Values and values education in Estonian preschool child care institutions, Journal of Teacher Education for Sustainability, Vol. 17, No 2, pp. 108-124, 2015.

[16] J. I. M. Carpendale. Piaget's theory of moral development. In U. Müller, J. I. M. Carpendale, \& L. Smith (Eds.), The Cambridge companion to Piaget, Cambridge University, pp. 270-286, 2009, Online available from https://doi.org/10.1017/CCOL9780521898584.012.

[17] W. Sanderse. The meaning of role modelling in moral and character education, Journal of Moral Education, Vol. 42, No 1, pp. 28-42, 2013.

[18] A. Sandberg, E. Ärlemalm-Hagsér. The Swedish national curriculum: Play and learning with fundamental values in focus, Australasian Journal of Early Childhood, pp. 36, No 1, pp. 34-50, 2011.

[19] A. Demidov, T. Melnikov, A. Moskvina, A. Tretyakov. The organization of ecological education of pre-school children by means of media literacy education: Theory, national policy, scientometrics and vectors of development, Media Education, Vol. 54, No 4, pp. 470-481, 2019, Online available from https://cyberleninka.ru/article/n/the-organiza tion-of-ecological-education-of-per-school-children-by-mea ns-of-media-literacy-education-theory-national-policy-scien tometrics/viewer 
[20] I. Komarova, A. Demidov, T. Komarova. The partial program of preschool education "What is good and what is bad" is an innovative educational product for the preschool education system, Integration of Media Education, Legal Education and Legal Informatization in Conditions of a Modern School, MOO "Informaciya dlya vsech", CENO RANCHiGS, Moscow, pp. 304-331, 2018.

[21] E. I. Elizova, N. A. Karataeva. Pedagogical potential of Russian folk tales in formation of cultural identity of preschool children, Advances in Social Science, Education and Humanities Research, Proceedings of the Internation Conference on Humanities and Social Sciences: Novations, Problems, Prospects, Vol. 333, pp. 189-194, 2019, Online available from https://doi.org/10.2991/hssnpp-19.2019.35

[22] P. Döge, H. Keller. Similarity of mothers' and pre-school teachers' evaluations of socialization goals in a cross-cultural perspective, Journal of Research in Childhood Education, Vol. 28, No 3, pp. 377-393, 2014.

[23] S. Lappalainen. Liberal multiculturalism and national pedagogy in a Finnish preschool context: Inclusion or nation - making? Pedagogy, Culture \& Society, pp. 99-112, 2006, doi: 10.1080/14681360500487777.

[24] N. Butenko. Conceptual Foundations of the Artistic and Aesthetic Development of Preschool Children, Diss. ... doc. of ped. sciences, Chelyabinsk, 2016.

[25] A. Nicu. Particularities of axiology in preschool education, Journal of Education Sciences and Psychology, Vol. VI, No LXVIII, pp. 196-203, 2016.

[26] L. Brovchak, L. Starovoit, L. Likhitska. Pedagogical conditions for creative and artistic development of children of senior preschool age by means of art, The New Educational Review, pp. 206-217, 2018, doi: 10.15804/tner.2018.52.2.16.

[27] O. Korzhenko, E. Zargaryan. Art pedagogy today: Goals and development prospects, theory and practice of education in the modern world, Materials of the III Intern. Scientific Conference, Renome, St. Petersburg, pp. 95-97, 2013.

[28] R. Brzezinska, L. Ishchenko, I. Kalynovska. Future teachers' axiological sphere development for children's creativity formation, Science and Education, Vol. 12, pp. 99-104, 2017.

[29] N. Sergeeva. Art pedagogy as a resource for the humanization of the school of the new century, Problems of art in the XXI century: The objectives of the school, Collection of Articles on the Materials of the International Scientific-Practical Conference, 2010.

[30] Y. Pavlenko, O. Vilkhova, N. Topchii. Elements of museum pedagogy in the teaching and education of children of preschool age and primary school age, Problem Space of Modern Society: Philosophical Communicative and Pedagogical Interpretations. Collective Monograph, part II, Warsaw, pp 505-518, 2019.

[31] I. Zhitnaya, A. Lysenko, A. Levshina, I. Kiseleva. Art pedagogy in preschool education: opportunities and challenges, International Scientific Conference: Achievements and Perspectives of Philosophical Studies, Vol. 72, 2019, Online available fromhttps://www.shs-confe rences.org/articles/shsconf/abs/2019/13/shsconf_appsconf2 019_04002/shsconf_appsconf2019_04002.html 